\title{
LA FORMACIÓN ALTO PALOMO: FLUJOS PUMÍTICOS DE LA CORDILLERA VOLCÁNICA CENTRAL, COSTA RICA
}

\author{
Adrián Villegas Fonseca \\ Instituto Costarricense de Electricidad, Apdo. 10032-1000, San José Costa Rica \\ adrianvf2003@yahoo.com
}

(Recibido 15/05/03; aceptado 21/09/03)

\begin{abstract}
The Alto Palomo Formation is divided in two members: Palomo (lower) and Palmitos (upper). Both are composed by pumice lapilli tuffs (pumice pyroclastic flows). There are also lithic or pumice basal breccias (co-ignimbritic lag breccias and air fall breccias). At the base of this sequence, there are in some localities thin layers of fine to medium-grained ashes (pyroclastic surges). The two members can be recognized according to their compositional differences: biotite and accretional lapilli in Palmitos Member and absence of them in Palomo Member. The distribution of the latter suggests its origin in La Picada Caldera. The distribution of components in Palmitos Member shows a strong control by paleo-valleys (observed thickness $\leq 100 \mathrm{~m}$ ) around La Vieja river. The occurrence of basal lithic and pumice breccias around this locality, suggests that this member originated from Chocosuela Caldera. Platanar volcano built its edifice on its southern rim.
\end{abstract}

Keywords: Central Volcanic Range, pumice flow, Alto Palomo Formation, basal breccias, co-ignimbrites, accretionary lapilli.

RESUMEN: La Formación Alto Palomo está dividida en dos miembros: Palomo el inferior y Palmitos el superior. Ambos están constituidos por tobas de lapilli pumíticos (flujos piroclásticos pumíticos). Tienen brechas basales líticas o pumíticas (brechas co-ignimbríticas de rezago y de caída). En algunos sitios, en la base de estas secuencias, se observan niveles delgados de cenizas finas a medias (oleadas piroclásticas), dando una secuencia típica de flujos ignimbríticos. Los dos miembros se reconocen por las diferencias composicionales: presencia de cristales de biotita y lapilli acrecional en el Miembro Palmitos y la ausencia de ellos en el Miembro Palomo. En el caso de este último, la distribución de los afloramientos y constituyentes evidencian una fuente de origen en la Caldera La Picada. La distribución de los constituyentes principales en el Miembro Palmitos muestra un control fuerte por los paleovalles (espesores observados $\leq 100 \mathrm{~m}$ ), hacia el río La Vieja, así como la ocurrencia de brechas basales líticas y pumíticas en esta localidad, asocian la depositación de este miembro con la formación de la Caldera Chocosuela. En su borde sur se edificó posteriormente el Volcán Platanar.

Palabras clave: Cordillera Volcánica Central, flujo pumítico, Formación Alto Palomo, brechas basales, coignimbritas, lapilli acrecional.

\section{INTRODUCCIÓN}

El presente trabajo tiene como objetivo describir, definir y correlacionar los depósitos pumíticos de la Formación Alto Palomo, observados entre la Cordillera Volcánica Central y la
Cordillera de Tilarán. Su litología ha sido descrita por Madrigal (1967) y por Alvarado \& Carr (1993), pero en estos trabajos se asociaron rocas piroclásticas disímiles. Villegas (1997) definió una secuencia de unidades, estableció las caracterizaciones formales de los tipos de 
rocas piroclásticas presentes, propuso una tentativa secuencia estratigráfica y fuentes de origen.

\section{LA FORMACIÓN ALTO PALOMO}

La formación se puede dividir en dos miembros: Palomo, el inferior, y Palmitos, el superior. Ambos pueden ser cartografiados y reconocidos en el campo según sus características composicionales (Fig. 1). Las características distintivas y composicionales de ambos miembros se detallan en los Cuadros 1 y 2.

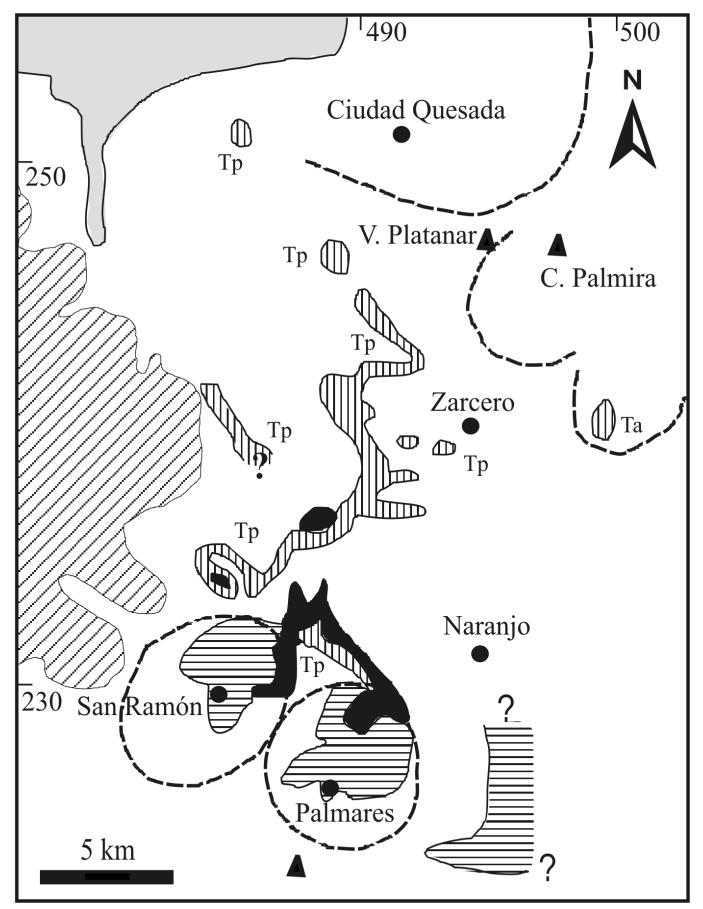

Sedimentos recientes

Formación Monteverde

Formación Tiribí

Lacustre Palmares

Formación Alto Palomo

(Ta Miembro Palomo, Tp Miembro Palmitos)

Rocas indiferenciadas

( $)$ Caldera

A Volcán

Fig. 1: Mapa geológico con la distribución de la Formación Alto Palomo.

\section{El Miembro Palomo}

\section{Litología}

Está constituido principalmente por tobas de lapilli pumíticos rojos, crema, amarillo y blancos, con mala a muy mala selección y contacto por matriz. Se trata de flujos piroclásticos pumíticos o ignimbritas sensu Sparks et al. (1973). Localmente se encuentran brechas basales pumíticas con poca ceniza fina, las cuales gradan a los depósitos de lapilli. Se trata de brechas ignimbríticas proximales o brechas coignimbríticas de rezago (según Wright, 1981). En la base se observan a veces niveles delgados de cenizas finas a medias productos de oleadas piroclásticas del tipo ground surge sensu Walker (1971). La existencia de gradaciones entre las brechas, lapilli y cenizas indica que corresponden con una misma secuencia eruptiva.

La presencia de estructuras de impacto en la base de la brecha pumítica, así como la presencia de una fracción gruesa importante, mal seleccionada, con finos principalmente hacia el techo del depósito, pueden indicar que se trata de una brecha co-ignimbrítica de caída (co-ignimbrite lag-fall deposits, sensu Druit \& Sparks, 1982). Las variaciones laterales de espesor que muestra la brecha pueden ser relacionadas con erosión hídrica o producida por el flujo de pómez, que produce un contacto neto erosivo ondulado a irregular entre estos niveles, indicando que se trata de eventos diferentes. La inexistencia de paleosuelos indica que una separación temporal entre uno y otro evento es muy corta.

\section{Tipos de constituyentes}

Los constituyentes están dominados por la pómez blanca a gris bandeada, con cristales de anfíboles, plagioclasa y feldespato potásico. Las pómez son subangulares a angulares, generalmente densas o con poca vesicularidad (5 - 30\%, máxima concentración dentro de la brecha pumítica basal), con tamaños promedio entre $4-10 \mathrm{~cm} \mathrm{y} \leq 40 \mathrm{~cm}$ en la brecha pumítica. Los líticos son principalmente fenoandesíticos 
Cuadro 1

Características de reconocimiento de la Formación Alto Palomo

\begin{tabular}{|c|c|c|c|}
\hline Miembro & $\begin{array}{c}\text { Características } \\
\text { primarias }\end{array}$ & $\begin{array}{c}\text { Características } \\
\text { secundarias }\end{array}$ & $\begin{array}{l}\text { Relaciones } \\
\text { estratigráficas }\end{array}$ \\
\hline Palomo & $\begin{array}{l}\text { Color café claro a blanco, } \\
\text { carencia completa de } \\
\text { cristales de biotita y lapilli } \\
\text { acrecional }\end{array}$ & $\begin{array}{l}\text { Múltiples eventos de corto } \\
\text { espesor, variable grado de } \\
\text { meteorización, suelos } \\
\text { residuales, presencia de } \\
\text { materia orgánica carbonizada. } \\
\text { Líticos adesíticos - dacíticos }\end{array}$ & $\begin{array}{l}\text { Sobreyace al Grupo } \\
\text { Aguacate, es sobreyacida } \\
\text { por el Miembro Palmitos }\end{array}$ \\
\hline Palmitos & $\begin{array}{l}\text { Color café a crema claro, } \\
\text { ocasionales lentes de pómez } \\
\text { y líticos. Ocasional pómez } \\
\text { colapsadas. Cristales de } \\
\text { biotita y anfibol en matriz, } \\
\text { nivel cinerítico o brecha } \\
\text { pumítica ( } 95 \% \text { pómez) en } \\
\text { la base }\end{array}$ & $\begin{array}{l}\text { Lapilli acrecional, materia } \\
\text { orgánica no carbonizada, } \\
\text { líticos dacíticos-andesíticos, } \\
\text { oleadas en la base, facies de } \\
\text { relleno de valle }\end{array}$ & $\begin{array}{l}\text { Sobreyace al Miembro } \\
\text { Palomo o Grupo } \\
\text { Aguacate, sobreyacida por } \\
\text { Lacustre de Palmares }\end{array}$ \\
\hline
\end{tabular}

\section{Cuadro 2}

Características composicionales de la Formación Alto Palomo

\begin{tabular}{|c|c|c|}
\hline & Unidad Palomo & Unidad Palmitos \\
\hline Pómez & $\begin{array}{l}\text { Blanca con anfíbol, } \\
\text { subredondeada - angular, } \leq 30 \% \text {, } \\
\text { ocasionalmente fracturadas, fibrosas, } \\
\text { bandeamiento ocasional }\end{array}$ & $\begin{array}{l}\text { Blanca, rosada y gris claro, con } \\
\text { cristales de plagioclasa, biotita } \\
\text { y anfíbol, vesículas irregulares } \\
\text { subparalelas, subredondeada, } \\
\text { subangular, a veces colapsadas, } \\
95 \% \text { en brecha basal, } 5-25 \% \\
\text { depósito lapíllico }\end{array}$ \\
\hline Líticos & $\begin{array}{l}\text { Andesitas, basaltos con cristales } \\
\text { de olivino, dacitas, } \leq 25 \%\end{array}$ & $\begin{array}{l}\text { Brecha basal: monzogranitos, } \\
\text { andesitas y dacitas, angulares a } \\
\text { subangulares, } 60 \% \text { max. Lapilli: } \\
\text { Fenoandesitas y fenodacitas, } \\
\text { angulares a subredondeados, } \\
\text { lapilli acrecional } \leq 20 \%\end{array}$ \\
\hline Matriz & $\begin{array}{l}\text { Blanca-café, lapilli fino a grueso, } \\
\text { rico en cristales de plagioclasa } \\
\text { y anfíbol }\end{array}$ & $\begin{array}{l}\text { Gris a crema, blanca, lapilli } \\
\text { grueso cinerítico en la base, } \\
\text { cristales de biotita y anfíbol }\end{array}$ \\
\hline Espesor & $25 \mathrm{~m}$ & 25-100 m, área 900 km² \\
\hline Fuente & Caldera La Picada & Caldera Chocosuela \\
\hline
\end{tabular}

con máximos dentro de las brechas basales (5$25 \%, 4-7 \mathrm{~cm})$, fenodacíticos $(1-5 \%, \leq 7 \mathrm{~cm}) \mathrm{y}$ fragmentos hidrotermalizados $(1-5 \%, \leq 5 \mathrm{~cm})$. Dentro de los paleosuelos se observa materia orgánica carbonizada $(\leq 10 \% \mathrm{y} \leq 1,5 \mathrm{~cm})$. La matriz está constituida por los mismos componentes de la fracción gruesa y cristales de plagioclasas.

\section{Estructuras internas}

Presentan desde una estratificación bien definida hasta una groseramente establecida, decimétrica a métrica, generalmente ondulada, con gradación positiva a inversa simétrica. Presentan fuertes variaciones de espesor, llegándose a acuñar. En la brecha pumítica basal 
se observan estructuras de impacto en la base. La ocurrencia de estructuras posdepositacionales, tales como pliegues y desarrollo de fallamiento, es ocasional (solo en los depósitos delgados).

\section{El Miembro Palmitos}

\section{Litología}

Está constituido por tobas de lapilli pumítico crema (Fig. 2), grises a blancos, con mala a muy mala selección y contacto por matriz, productos de flujos piroclásticos. Hay brechas basales pumíticas con ausencia relativa de finos, los cuales están en gradación con los depósitos de lapilli (brechas ignimbríticas proximales o coignimbríticas). En algunos sitios, en la base de esta secuencia se observan niveles delgados de cenizas finas a medias conformadas por oleadas piroclásticas. La existencia de gradaciones entre los tipos de depósitos indica que corresponden con una misma secuencia eruptiva.

\section{Tipos de constituyentes}

Los más abundantes (5-25\%; en la brecha pumítica basal hasta un máximo del 95\%) son pómez blanca, rosada y gris bandeada, con cristales de anfíboles, biotita, plagioclasa y feldespato potásico; subredondeada a subangular, con vesículas generalmente más grandes hacia el centro, con tamaños variables entre 2 y $16 \mathrm{~cm}(\leq 40 \mathrm{~cm}$ en la brecha pumítica). Dentro de la brecha pumítica basal, la pómez rosada alcanza tamaños individuales mayores que la pómez blanca $(11 \mathrm{vs} .8 \mathrm{~cm})$

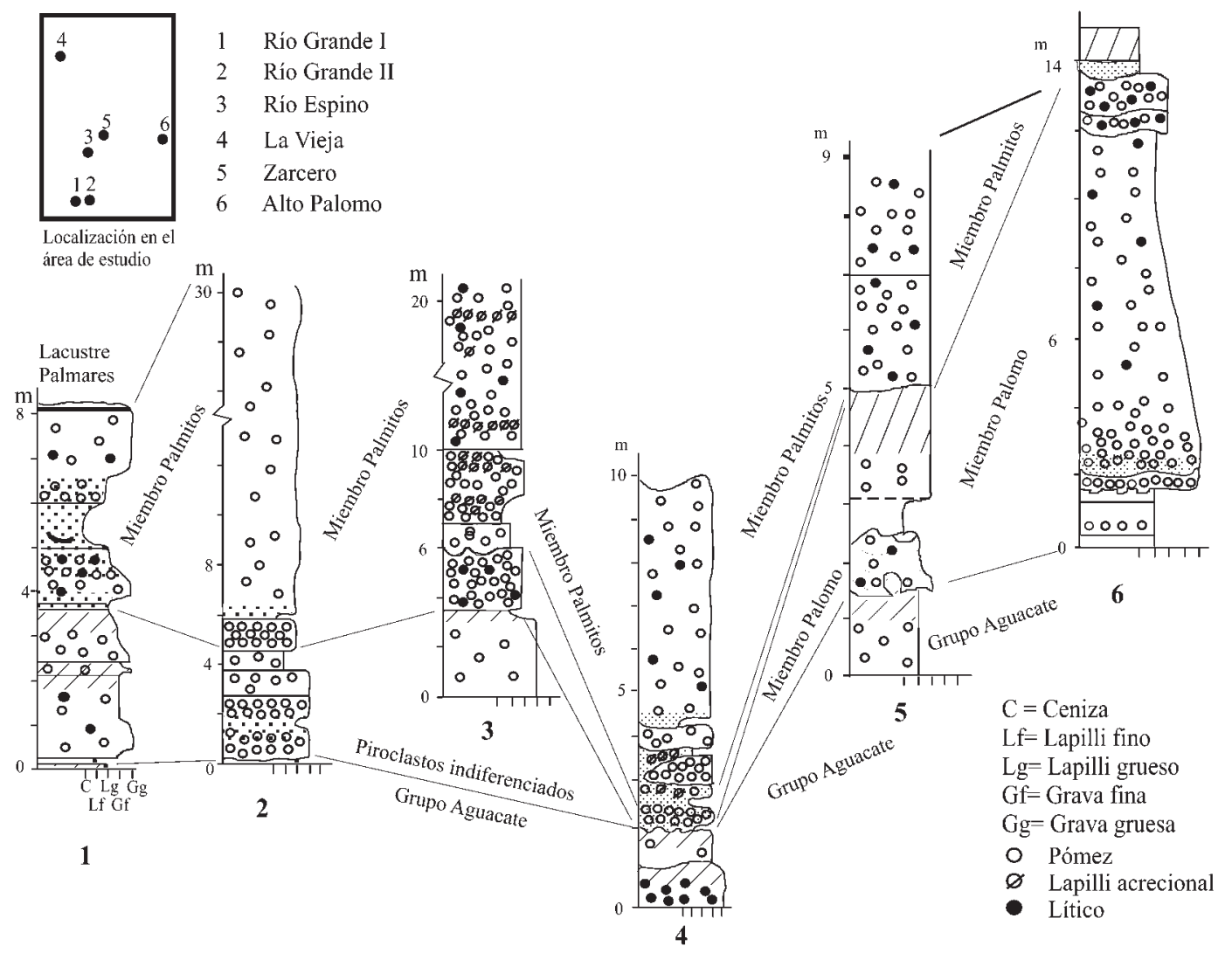

Fig. 2: Correlación de columnas estratigráficas de los depósitos de los miembros Palomo y Palmitos. 
pero una frecuencia volumétrica menor (1 vs. $29 \%$ ); además, las pómez rosadas presentan una vesicularidad mayor en forma de vacuolas alargadas y fibrosas. La pómez gris presenta una concentración mayor de cristales de plagioclasa y feldespatos potásicos. Los líticos son principalmente fenoandesíticos, ocasionalmente vesiculados $(<4 \%,<2 \mathrm{~cm}$ en la brecha pumítica; 5-25\%, 4$7 \mathrm{~cm}$ en el flujo piroclástico), intrusivos ácidos $(<40 \mathrm{~cm})$ en la brecha lítica basal, fenodacíticos $(1-5 \%, \leq 7 \mathrm{~cm})$, clastos hidrotermalizados $(1-5 \%$, $\leq 5 \mathrm{~cm}$ ) en el flujo. Dentro de la brecha lítica basal se observa una diferenciación vertical de los líticos: intrusivos ácidos e hidrotermalizados en
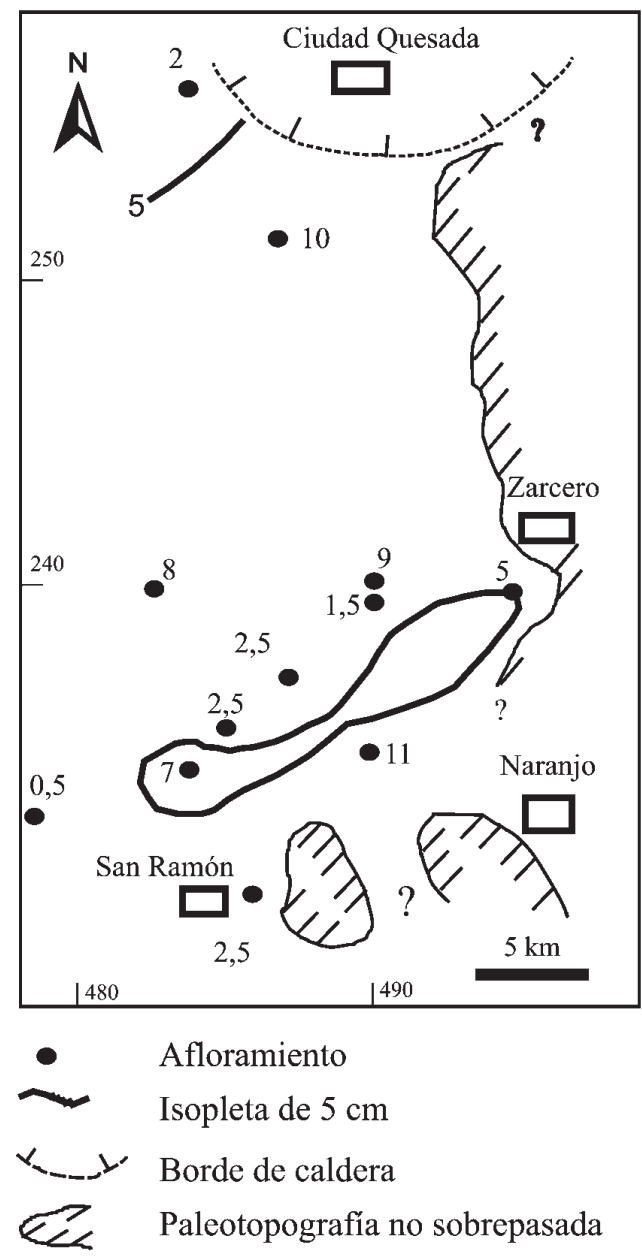

Fig. 3: Puntos de observación y curva isopleta de $5 \mathrm{~cm}$ de la pómez del Miembro Palmitos. la base y fenodacíticos en la parte superior. Se puede inferir que los primeros pueden constituir parte de las paredes y techo de la cámara magmática o del conducto eruptivo, cognatos y cumulitos. Las figuras 3 y 4 muestran los valores máximos de pómez y líticos y algunas isopletas.

Otro constituyente que se presenta dentro de la toba de lapilli pumítico y que la caracteriza, son los lapilli acrecionales elongados $(\leq 2 \mathrm{~cm})$, con el núcleo prominente. En la base y techo de esta toba, ocurren en niveles de $20 \mathrm{~cm}$ de espesor con hasta $30 \%$ de lapilli. En el resto del depósito, se encuentran diseminados $(\sim 2 \%)$, presentándose frecuentemente como fragmentos.

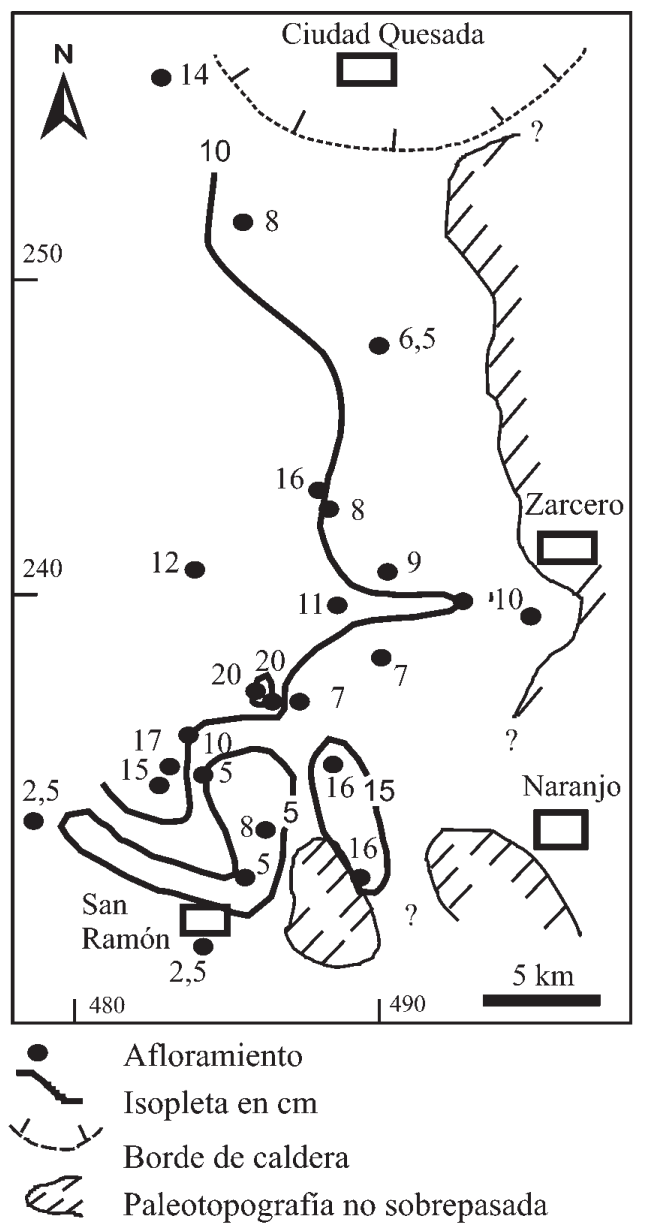

Fig. 4: Puntos de observación y curvas isopletas de los líticos del Miembro Palmitos. 
Estos lapilli acrecionales elongados son del tipo lapilli acrecional de núcleo, característicos de zonas distales de flujos piroclásticos (Schumacher \& Schmincke, 1991). Se produce en la interfase entre la zona de elutriación y la zona de segregación de un flujo piroclástico, con temperaturas que pueden superar los $130^{\circ} \mathrm{C}$ (Schumacher \& Schmincke, 1995). Los lapilli acrecionales cerca del contacto superior pueden generarse en la nube acompañante (co-ignimbrite ashfall) y depositados por caída en el mismo sitio de la aparición, mientras que los generados en la interfase referida, son transportados por el flujo a una relativa distancia. Evidencia de este transporte puede ser la presencia de fragmentos de lapilli acrecional en contacto con lapilli enteros en la parte superior del depósito acorde con la formación del núcleo de los lapilli durante el desplazamiento lateral (Schumacher \& Schmincke, 1995).

La matriz de las brechas basales está constituida por los mismos componentes de la fracción gruesa más cristales de biotita y anfíboles $(<5 \%)$. En la toba de lapilli pumítico, la matriz está constituida por ceniza gris a crema, más cristales de biotita y anfíbol con fragmentos de pómez y líticos pequeños.

\section{Estructuras internas}

Las estructuras primarias principales son estratificación decimétrica a centimétrica en ocasiones ondulada, lenticulaciones de estratos o constituyentes (principalmente pómez), laminaciones y gradaciones. En los afloramientos con los espesores mayores se puede observar una disminución de la granulometría hacia el sector medio del depósito. En ocasiones esta variación se observa como niveles de estratificación, lo cual indicaría la presencia de varios pulsos dentro de la erupción (Walker, 1985). Las estructuras secundarias son fallamientos y diaclasamientos, principalmente normales, los cuales se incrementan hacia el río La Vieja. Igualmente, se incrementan los desplazamientos, en algunos casos métricos, en el piso de este miembro, no así para los niveles superiores, evidenciando un comportamiento sindepositacional. En algunos casos las fracturas se presentan rellenas de una mezcla de pómez y fracciones finas de los constituyentes.

\section{DISTRIBUCIÓN, RELACIONES ESTRATIGRÁFICAS Y ESTRATOTIPOS}

Los miembros descritos se distribuyen en la depresión entre la Cordillera de Tilarán y las estribaciones occidentales de la Cordillera Volcánica Central, entre las localidades de Ciudad Quesada y Palmares, San Ramón y Zarcero (Fig 1). La ocurrencia en algunos casos se reduce a relictos de erosión para el Miembro Palomo (el inferior), mientras que el Miembro Palmitos se presenta de manera tabular entre Palmares y Zarcero y en forma de relictos de erosión entre La Peña de Zarcero y Ciudad Quesada. Dadas estas naturalezas de afloramiento, poseen un espesor irregular entre los $15 \mathrm{y}$ los $100 \mathrm{~m}$, con relleno de paleovalles.

Ambos miembros sobreyacen de manera discordante al Grupo Aguacate, algunos piroclásticos indiferenciados y a la Formación Monteverde (Fig. 5), y son sobreyacidas principalmente

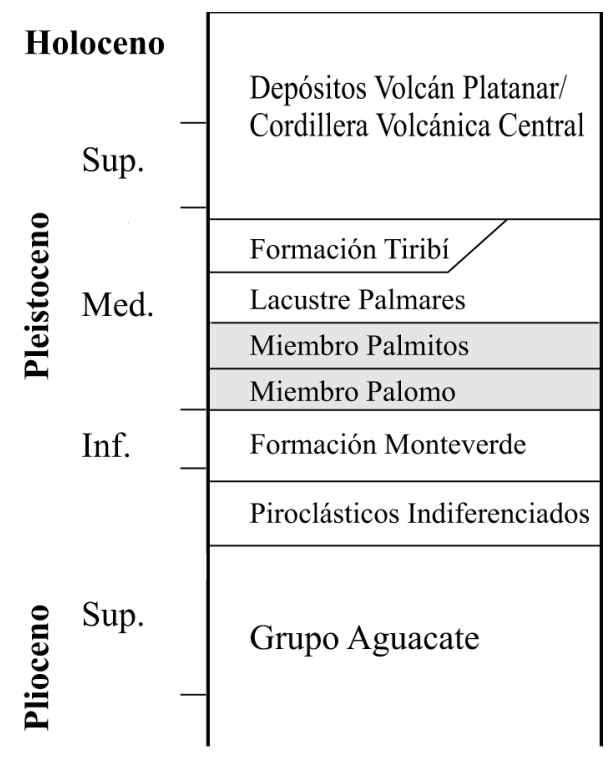

Formación Alto Palomo

Fig. 5: Columna estratigráfica regional y posición de la Formación Alto Palomo. 
por los productos sedimentarios del Lacustre de Palmares y en menor grado por los productos volcánicos indiferenciados de la Cordillera Volcánica Central. Dada la posición estratigráfica observada, se infiere una edad de formación dentro del Pleistoceno Medio (Fig. 5).

Como localidades tipo se definen, para el Miembro Palmitos, el Río La Vieja (coordenadas $483,4 \mathrm{E}-256,95 \mathrm{~N}$ ) y para el Miembro Palomo el sitio con coordenadas 502,0 E - 241,5 N. Como paraestratotipo para el Miembro Palmitos, el afloramiento en las coordenadas. 239,3E $493,5 \mathrm{~N}$.

\section{TEMPERATURA Y VELOCIDAD DE LOS FLUJOS PIROCLÁSTICOS}

Dentro del Miembro Palomo, se observa ocasionalmente la presencia de materia orgánica carbonizada y partes soldadas, que indicarían una depositación para algunos de los pulsos de este miembro, con temperaturas superiores a los $400^{\circ}$ C (Cas \& Wright, 1991; Fisher \& Schmincke, 1984). En el caso del Miembro Palmitos se encuentran ocasionalmente restos de materia orgánica preservada en forma de moldes que evidenciarían temperaturas inferiores a $400^{\circ} \mathrm{C}$. La presencia de lapilli acrecional indica de igual manera una temperatura baja en el flujo piroclástico. La oleada piroclástica (ground surges) en el Miembro Palmitos, se originarían en estados calientes y secos, por lo tanto depositados a más de $100^{\circ} \mathrm{C}$ (Carey, 1991).

Sólo se disponen de datos suficientes para calcular la velocidad de los flujos del Miembro Palmitos, que se infiere sobrepasó obstáculos de gran elevación. La máxima diferencia de elevación observada es de $1100 \mathrm{~m}$, lo que posibilita calcular la velocidad mínima a la cual pudo desplazarse el flujo según la fórmula deducida por Wilson \& Walker (1981): $\mathrm{gh}=\mathrm{v}^{2} / 2$. Con el dato indicado antes, la velocidad mínima de este flujo pumítico debió de ser de $147 \mathrm{~m} \mathrm{~s}^{-1}$ $\left(529 \mathrm{~km} \mathrm{~h}^{-1}\right)$. Los mismos autores indican una serie de evidencias cualitativas para una alta movilidad en un flujo. Para este miembro se cumplen la no evidencia de erosión reconocible en el piso del depósito, y las facies de relleno de valles.

\section{MECANISMO DE TRANSPORTE Y DEPOSITACIÓN}

Las estructuras internas observadas en los flujos piroclásticos de los dos miembros indican que la depositación se dio a partir de un flujo que se movía de manera laminar o en forma de capas con ausencia de turbulencia (estratificación observada), producida en un corto espacio de tiempo entre el colapso de la columna eruptiva y la formación del flujo (Wright \& Walker, 1981). Según lo referido por estos autores, la concentración de partículas debió ser relativamente alta, para que se pueda preservar las estructuras internas (estratificaciones).

Las brechas basales observadas en ambos miembros presentan una constitución casi enteramente a partir de pómez o líticos, producto de un flujo con extrema segregación. Este alto nivel de segregación se caracteriza por la elutriación de los finos y por consiguiente, la formación de un depósito caracterizado por su empobrecimiento (Wilson, 1980), correspondiendo con un flujo del tipo 3, segregado, según Druit \& Sparks (1982). La formación de las brechas basales en estos miembros está relacionado con las fases de mayor vigor y tasas de descarga en el emplazamiento de una ignimbrita (Scandone, 1990).

\section{ÁREAS FUENTE}

Los depósitos del Miembro Palomo muestran un engrosamiento del espesor hacia el este, así como una distribución radial alrededor de la fila El Gorrión. La presencia de brechas proximales en estas localidades puede indicar una fuente de origen en esta fila. Por las condiciones de depositación y afloramiento de los productos generados, la caldera se infiere de pequeño diámetro, denominada La Picada. Con la depositación de este miembro, el volcanismo de esta parte de la Cordillera Volcánica Central cesa prácticamente hasta la fecha. 
En el caso del Miembro Palmitos, la distribución de líticos y pómez (Figs. 3 y 4), presenta un incremento de los diámetros hacia el oeste, fuertemente controlados por la paleotopografía existente, indicando un área fuente no muy bien definida. Aun así, la presencia de brechas co-ignimbríticas en la base del miembro, localizadas en los afloramientos más cercanos al Río La Vieja (zona norte del área), así como la existencia de fallamiento normal sindepositacional en el área de depositación de esta brecha indicarían un área fuente muy cercana, representada por el alineamiento del Río La Vieja (borde volcanotectónico) observable en las imágenes de satélite y las fotografías aéreas como un estructura semicircular abierta al noroeste, de $20 \mathrm{~km}$ de diámetro, con la presencia de un centro eruptivo neógeno al borde sureste (Volcán Platanar). Esta estructura ya fue referida anteriormente como caldera Chocosuela (Alvarado \& Carr, 1993).

Según la fórmula dada por Spera \& Crisp (1981), $\mathrm{V}=0,28^{*} \mathrm{~S}^{1,1}$, donde $\mathrm{S}$ corresponde con el área de la caldera, el volumen así obtenido de roca densa equivalente para la Caldera Chocosuela, es de $156 \mathrm{~km}^{3}$. Calderas del tamaño de la Chocosuela se presentan solo en condiciones tectónicas relacionadas con complejos de fallas curvas (ring complexes) en sitios epicontinentales (Walker, 1984). La estructura principal en la cual parece estar contenida esta caldera posee una anomalía gravimétrica negativa entre 15 y -40 mGal, con valores máximos al sureste, en el volcán Platanar (Kellogg \& Vega, 1995). Similares valores de anomalías gravimétricas se han encontrado en calderas reconocidas en diferentes partes del mundo (Wilson et al., 1984).

\section{CONCLUSIONES}

La Formación Alto Palomo, del Pleistoceno Medio, está constituida por dos miembros: Palomo el inferior, y Palmitos el superior. Los depósitos de los miembros Palomo y Palmitos están caracterizados por flujos piroclásticos pumíticos (ignimbritas), con brechas coignimbríticas de caída o de rezago y oleadas en su base (ground surges cineríticos).
Para el Miembro Palmitos se pudo estimar la velocidad mínima del flujo piroclástico en 147 $\mathrm{m} \mathrm{s}^{-1}\left(529 \mathrm{~km} \mathrm{~h}^{-1}\right)$. En el Miembro Palomo, la presencia de materia orgánica carbonizada indica una temperatura de emplazamiento superior a los $400^{\circ}$ C. En el caso del Miembro Palmitos, la presencia de materia orgánica no carbonizada, así como la ocurrencia de lapilli acrecional y la formación de dunas en los ground surges parecen indicar que este miembro se depositó a una temperatura en el ámbito $100-400^{\circ} \mathrm{C}$.

Las fuentes de origen para ambos miembros son diferentes: Una posible caldera en la fila El Gorrión, denominada La Picada, para el Miembro Palomo, y la caldera de Chocosuela para el Miembro Palmitos.

\section{REFERENCIAS}

ALVARADO, G.E. \& CARR, M.J., 1993: The PlatanarAguas Zarcas volcanic centers, Costa Rica: Spatialtemporal association of Quaternary calc-alkaline and alkaline volcanism. - Bull. Volcanol. 55: 443-453.

CAREY, G., 1991: Transport and depositation of tephra by pyroclastic flows and surges. - En: FISCHER, H. \& SMITH, G. (eds.): Sedimentation in volcanic settings. - SEPM, USA, Spec. Publ. 45: 39-58.

CAS, R.A.F. \& WRIGHT, J.V., 1991: Subaqueos pyroclastic flows and ignimbrites: An assessment. - Bull. Volcanol. 53: 357-380.

DRUIT, T. \& SPARKS, R., 1982: A proximal ignimbrite breccia facies on Santorini, Greece. - J. Volcanol. Geotherm. Res. 13: 147-171.

FISHER, R.V. \& SCHMINCKE, H-U., 1984: Pyroclastic rocks. - 472 págs. Springer, Berlin.

KELLOGG, J. \&VEGA, V., 1995: Tectonic development of Panama, Costa Rica and the Colombian Andes: Constraints from global positioning system geodetic studies and gravity. - En: MANN, P. (ed.): Geologic and tectonic development of the Caribbean Plate boundary in Southern Central America. - Geol. Soc. Amer. Spec. Pap. 295: 75-90.

MADRIGAL, R, 1967: Estudio geológico y evaluación de algunos yacimientos de piedra pómez en Costa Rica. Notas Téc. y Geol. MEIC, 26 págs.

SCANDONE, R., 1990: Chaotic collapse of calderas. - J. Volcanol. Geotherm. Res. 42: 285-302. 
SCHUMACHER, R. \& SCHMINCKE, H-U., 1991: Internal structure and occurrence of accretionary lapilli: A case study at Laacher See volcano. - Bull. Volcanol. 53: 612-634.

SCHUMACHER, R. \& SCHMINCKE, H-U, 1995: Model for the origin of accretionary lapilli. - Bull. Volcanol. 56: 626-639.

SPARKS, R.S.J., SELF, S. \& WALKER, G.P.L., 1973: Products of ignimbrite eruptions. - Geology, 1(11): 115-118.

SPERA, F.J. \& CRISP, J.A., 1981: Eruption volume, periodicity and caldera area: Relationships and inferences on development of compositional zonation in silicic magma chambers. - J. Volcanol. Geotherm. Res. 11: 169-187.

VILLEGAS, A., 1997: Geodinámica de la Cordillera de Tilarán, relación entre la volcanología y la tectónica. 188 págs. Univ. de Costa Rica, San José [Tesis Lic.].

WALKER, G.P.L., 1971: Grain-size characteristics of pyroclastic deposits. - J. Geol. 79: 696-714.

WALKER, G.P.L., 1984: Downsag calderas, ring faults, caldera sizes and incremental caldera growth. - J. Geophys. Res. 89(B10): 8407-8416.
WALKER, G.P.L., 1985: Origin of coarse lithic breccias near ignimbrite source vents. - J. Volcanol. Geotherm. Res. 25: 157-171.

WILSON, C.J.N., 1980: The role of fluidization in the emplacement of pyroclastic flows: an axperimental approach. - J. Volcanol. Geotherm. Res. 76: 5596-5614.

WILSON, C.J.N. \& WALKER, G.P.L., 1981: Violence of pyroclastic flows eruptions. - En: SELF, S. \& SPARKS, S. (eds.): Tephra studies. - Riedel Publishing Company: 441-448.

WILSON, C., ROGAN, A.; SMITH, Y.; NORTHEY, D. \& HOUGHTON, B., 1984: Caldera volcanoes of the Taupo Volcanic Zone, New Zealand. - J. Geophys. Res. 89(B10): 8463-8484.

WRIGHT, J.V., 1981: The Rio Aguacaliente ignimbrite: Analysis of a compound intraplinian ignimbrite from a major late Quaternary Mexican eruption. - Bull. Volcanol. 44(2): 189-212.

WRIGHT, J.V., \& WALKER, G.P.L., 1981: Eruption, transport and depositation of ignimbrite: a case study from México. - J. Volcanol. Geotherm. Res. 9: 111-131. 